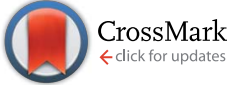

Cite this: Chem. Sci., 2017, 8, 1653

Received 12th October 2016 Accepted 8th November 2016

DOI: $10.1039 / \mathrm{c} 6 \mathrm{sc} 04565 \mathrm{k}$

rsc.li/chemical-science

\section{To catalyze or not to catalyze: elucidation of the subtle differences between the hexameric capsules of pyrogallolarene and resorcinarene $\uparrow$}

\author{
Qi Zhang, ${ }^{a}$ Lorenzo Catti, ${ }^{a}$ Ville R. I. Kailac and Konrad Tiefenbacher*ab
}

The closely related, self-assembled resorcinarene and pyrogallolarene capsules display contrasting and puzzling encapsulation behaviors. Herein, we elucidate the reasons for these differences by combining experimental studies and DFT calculations. Furthermore, we report that, in contrast to the resorcinarene capsule, the pyrogallolarene derivative is not capable of catalyzing reactions with cationic transition states. The molecular mechanisms responsible for these observations are probed in detail.
The functional mimicking of natural enzymes has been a very fascinating but also challenging research topic for decades. Several supramolecular structures have been identified that are able to catalyze reactions inside their enzyme-like pockets. ${ }^{1}$ Nevertheless, neither the catalytic efficiency nor the selectivity of such systems, can usually compete with natural enzymes. Therefore, the refinement of known structures, as well as the development of new systems, is necessary. For the design of new artificial enzyme-like catalysts, it is of fundamental importance to understand the prerequisites for catalytic activity. $\mathrm{We}^{2}$ and others ${ }^{3}$ have shown that the hexameric resorcinarene capsule $\mathbf{I}{ }^{4}$ which self-assembles from six units of resorcinarene 1 and eight water molecules (Fig. 1), is an efficient catalyst for a variety of cationic reactions. Nevertheless, the reasons for the high catalytic efficiency remain unclear. To learn more about the pivotal requirements for the catalytic activity of hexamer I, we became interested in the structurally closely related pyrogallolarene hexamer II. ${ }^{5}$ It self-assembles from six units of pyrogallolarene 2. Surprisingly, hexamer II displays a different encapsulation behavior compared to I in chloroform solution. It was reported that hexamer I encapsulates both tertiary amines as well as alkylammonium species, ${ }^{4 \boldsymbol{c}, \boldsymbol{d}, \mathbf{6}}$ while II only binds tertiary amines. ${ }^{\boldsymbol{e}, \boldsymbol{h}}$ Very recently, the Cohen group disclosed that binding of ammonium salts in II can be observed to some extent in benzene solution. ${ }^{7}$ The high affinity of ammonium salts for $\mathbf{I}$ can be explained by strong cation- $\pi$ interactions. However, the surprising exclusion of alkylammonium species from II in

${ }^{a}$ Department of Chemistry, University of Basel, St. Johannsring 19, CH-4056 Basel, Switzerland. E-mail: konrad.tiefenbacher@unibas.ch

${ }^{b}$ Department of Biosystems Science and Engineering, ETH Zürich, Mattenstrasse 26, CH-4058 Basel, Switzerland. E-mail: tkonrad@ethz.ch

${ }^{c}$ Department of Chemistry, Technical University of Munich, Lichtenbergstrasse 4, 85747 Garching, Germany

† Electronic supplementary information (ESI) available. See DOI: $10.1039 / \mathrm{c} 6 \mathrm{sc} 04565 \mathrm{k}$ chloroform solution remained puzzling, ${ }^{4 g}$ especially since encapsulated tertiary amines were completely expelled after protonation by the addition of acid. ${ }^{5 e, \boldsymbol{h}}$ This seemingly contradictory encapsulation behavior of II has remained a mystery for the last decade. We herein elucidate the reasons for these differences in chloroform solution. Importantly, we report that capsule II is catalytically completely incompetent in cationic reactions which are efficiently accelerated inside I and probe the molecular mechanisms responsible for these surprising observations.

Our interest in capsule II started with the observation that, while I is an efficient catalyst for cationic reactions, hexamer II is catalytically incompetent in such reactions. The tail-to-head
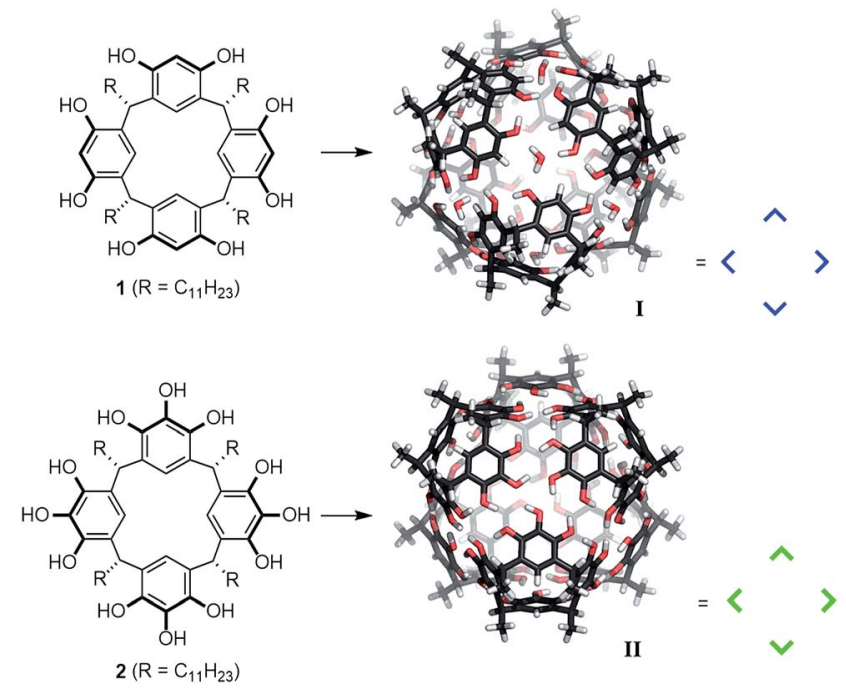

Fig. 1 Structures of hexameric resorcinarene I and pyrogallolarene II capsules, optimized at the density functional theory (DFT: PBE-D3/ def2-SVP) level and their respective building blocks 1 and 2 . 


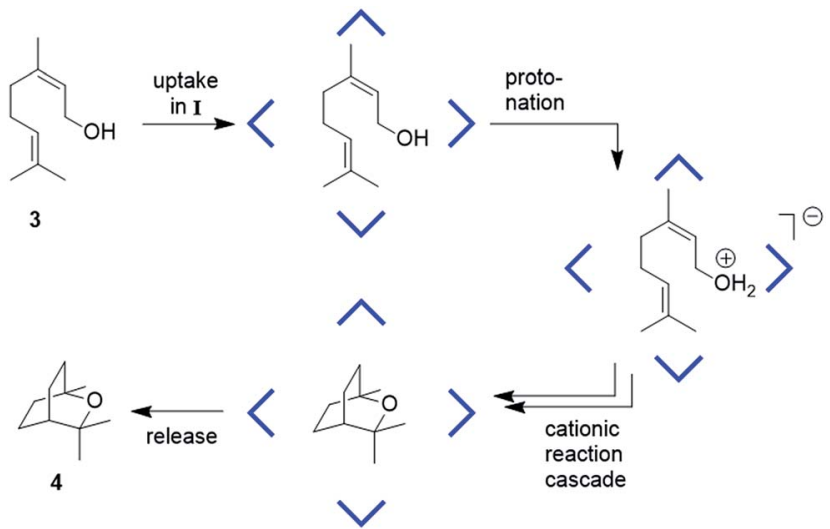

Fig. 2 Schematic overview of the proposed mechanism for the cyclization of nerol (3) to eucalyptol (4), catalyzed inside capsule I $\left(\mathrm{CDCl}_{3}, 30^{\circ} \mathrm{C}\right)^{2 \mathrm{c}}$

terpene cyclization of nerol (3) $)^{2 c}$ (Fig. 2) was investigated more closely with II. ${ }^{1} \mathrm{H}$-NMR analysis confirmed the formation of the host-guest complex 3@II (ESI-Fig. 14†). Therefore, the guest uptake cannot explain its catalytic inertness.

We first probed whether the absence of catalytic activity of II could arise from the reported resistance to bind alkyl ammonium salts, ${ }^{5 e}$ which may indicate a lack of cation $-\pi$ stabilization inside the cavity. A cation- $\pi$ stabilization of cationic transition states has been proposed as a possible reason for rate acceleration inside $\mathbf{I},{ }^{2 c}$ and may thus be a potential explanation for the observed catalytic differences. Interestingly, however, it was reported that tertiary amines bind well inside $\mathbf{I I} .^{\mathbf{s e}, \boldsymbol{h}}$ Recently, we demonstrated that a proton transfer from capsule I to the tertiary amines is responsible for their high affinity for $\mathbf{I}^{2 a}$ This raised the question of whether the same is true inside II. Therefore, we investigated the encapsulation of differently sized tertiary amines inside II. The encapsulation of triethylamine (5a) in II is clearly evident in the ${ }^{1} \mathrm{H}$-NMR spectrum (ESI-Fig. $1 \dagger$ ). The integral of the phenolic groups of II diminishes upon treatment with $\mathbf{5 a}$, while a new broad peak emerges between 3 and $7 \mathrm{ppm}$. Careful integration (ESI-Schemes 1 and 2, Table $2 \dagger$ ) reveals that it accounts for the diminished phenolic protons, as well as for the water signal, which is no longer visible as a separate peak. These observations are consistent with our previous findings for capsule I, and thus indicate the concomitant protonation of tertiary amines upon encapsulation in $\mathbf{I I}^{2 a}$ The integrity of the hexameric encapsulation complex was confirmed by DOSY spectroscopy (ESI-Fig. $2 \dagger$ ). Therefore, the formation of smaller (dimeric, or monomeric) pyrogallolarenecation complexes observed in methanol solution ${ }^{5 c}$ and in the solid state ${ }^{5 g, 8}$ can be excluded.

The size of the tertiary amine has a pronounced effect on protonation and encapsulation, as shown in Table 1a. The degree of protonation and encapsulation drops with the increasing size of the alkyl groups, a behavior that is consistent with a decreased cation- $\pi$ interaction due to steric shielding. In the case of triethylamine (5a), the deprotonation degree of II is considerably lower than the encapsulation degree. Therefore, a [5H5] $]^{+}$III ${ }^{-}$ complex, also observed in capsule $\mathbf{I},{ }^{2 a}$ is likely formed.
Table 1 Encapsulation studies with 1 eq. of (a) amine 5 with capsule II and (b) ammonium compounds 6 with capsules I and II. The encapsulation of the ammonium guest by capsule II was increased by the addition of the large amine base 7

\begin{tabular}{|c|c|c|c|}
\hline & $\mathbf{R}$ & $\begin{array}{l}\text { Deprotonation } \\
\text { degree of II }\end{array}$ & $\begin{array}{l}\text { Encapsulation } \\
\text { degree of } 5\end{array}$ \\
\hline $5 \mathbf{a}$ & $\mathrm{C}_{2} \mathrm{H}_{5}$ & $29 \pm 2 \%$ & $44 \pm 2 \%$ \\
\hline $5 b$ & $\mathrm{C}_{3} \mathrm{H}_{7}$ & $19 \pm 1 \%$ & $22 \pm 1 \%$ \\
\hline $5 c$ & $\mathrm{C}_{4} \mathrm{H}_{9}$ & $12 \pm 1 \%$ & $15 \pm 1 \%$ \\
\hline $5 d$ & $\mathrm{C}_{6} \mathrm{H}_{13}$ & $10 \pm 1 \%$ & $7 \pm 1 \%$ \\
\hline
\end{tabular}

(b)

\begin{tabular}{lllll}
\hline & & \multicolumn{2}{l}{ Encapsulation degree of $\mathbf{6}^{+}$by } \\
\cline { 3 - 5 } & $\mathbf{R}$ & $\mathbf{I}$ & II & $\begin{array}{l}\text { II, } \\
\text { after addition of } 7\end{array}$ \\
\hline $\mathbf{6 a}^{+} \mathbf{B r}^{-}$ & $\mathrm{C}_{2} \mathrm{H}_{5}$ & $100 \%$ & $\mathrm{nd}^{a}$ & $\mathrm{nd}^{a}$ \\
$\mathbf{6 b}^{+} \mathbf{B r}^{-}$ & $\mathrm{C}_{3} \mathrm{H}_{7}$ & $100 \%$ & $4 \pm 0.3 \%$ & $46 \pm 2 \%$ \\
$\mathbf{6 c}^{+} \mathbf{B r}^{-}$ & $\mathrm{C}_{4} \mathrm{H}_{9}$ & $100 \%$ & $0 \%$ & $30 \pm 1 \%$ \\
$\mathbf{6 d}^{+} \mathbf{B r}^{-}$ & $\mathrm{C}_{6} \mathrm{H}_{13}$ & $41 \pm 1 \%$ & $0 \%$ & $10 \pm 1 \%$
\end{tabular}

${ }^{a}$ Precipitation occured (2:1 complex, ESI-Table 3).

These results indicate that capsule II encapsulates amines in their protonated form and therefore is able to stabilize cations inside its cavity. Indeed, our quantum chemical density functional theory (DFT) calculations also indicate that capsule II stabilizes cations as well as or even more strongly than capsule I (within $c a$. 4-12 kcal mol${ }^{-1}$ for $\mathrm{NEt}_{4}^{+}$; see ESI-Table $4 \dagger$ ). This seems to contradict the previous observation that the ammonium salt $\mathrm{Hex}_{4} \mathrm{NBr}\left(\mathbf{6 d}^{+} \mathbf{B r}^{-}\right)$was rejected by capsule $\mathbf{I I} .{ }^{5 e}$ We therefore repeated the encapsulation studies not only with $\mathbf{6} \mathbf{d}^{+} \mathbf{B r}{ }^{-}$but with differently sized ammonium salts (Table $1 \mathrm{~b}$ ). The small ammonium salt $\mathrm{Et}_{4} \mathrm{NBr}\left(\mathbf{6 a}^{+} \mathbf{B r}^{-}\right)$is indeed encapsulated to a considerable extent (see ESI-Fig. $5 \dagger$ ). However, quantification was hampered by precipitation of a dimeric complex (see ESI-Table $3 \dagger$ ). With the increasing size of the alkyl residues, encapsulation drops dramatically: only $4 \%$ encapsulation is observed in the case of $\operatorname{Pr}_{4} \mathrm{NBr}\left(\mathbf{6 b}^{+} \mathbf{B r}^{-}\right)$, while the longer ammonium salts $\mathrm{Bu}_{4} \mathrm{NBr}\left(\mathbf{6 c}^{+} \mathbf{B r}^{-}\right)$and $\mathrm{Hex}_{4} \mathrm{NBr}\left(\mathbf{6 d}^{+} \mathbf{B r}^{-}\right)$ do not show any degree of uptake inside II. This confirms the earlier observation that larger ammonium salts are rejected by II, but also demonstrated that the uptake of the smaller salts is possible. Nevertheless, there is a striking difference between the capsules, as I encapsulates salts $\left(\mathbf{6} \mathbf{a}-\mathbf{6} \mathbf{c}^{+} \mathbf{B r} \mathbf{r}^{-}\right)$quantitatively and $\mathbf{6 d}^{+} \mathbf{B r}^{-}$to a large extent (see, ESI-Fig. $4 \dagger$ ). This discrepancy is even more surprising considering that our DFT calculations suggest an even stronger stabilization of cations inside II relative to I. To elucidate the different behavior of I and II, we calculated the electrostatic potential (ESP) map of the capsules' 
inner surfaces. As shown in Fig. 3, the main difference between the two systems are high potential areas on the inner surface of I, which represent positively charged hydrogen atoms of the bound water molecules. These could potentially stabilize the anions of encapsulated ammonium salts via hydrogen bonds. Such a stabilization of anions inside II is lacking, and could therefore explain the dramatically weaker binding of ammonium salts. Our DFT optimizations of the capsules in presence

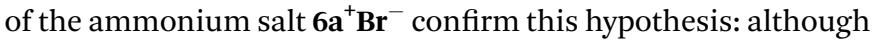
capsule II stabilizes cations better than capsule I, capsule II binds the ammonium salt weaker (ca. 3-9 $\mathrm{kcal} \mathrm{mol}^{-1}$, see ESITable $4 \dagger$ ) than $\mathbf{I}$.

The energetically unfavorable encapsulation of anions inside II raises the question of whether the anion is encapsulated at all. Its presence would weaken the cation- $\pi$ interactions, as has been shown in cyclophane hosts in organic solvents of low dielectric constants. ${ }^{9}$ Therefore the ammonium salt $\mathrm{EtPr}_{3} \mathrm{~N}^{+} \mathbf{M e S O}_{3}{ }^{-}\left(\mathbf{6} \mathbf{e}^{+} \mathbf{M e S O}_{3}{ }^{-}\right)$containing an organic anion, detectable by ${ }^{1} \mathrm{H}$ and ${ }^{13} \mathrm{C}$-NMR spectroscopy, was investigated. ${ }^{1} \mathrm{H}$ - and ${ }^{13} \mathrm{C}-\mathrm{NMR}$ investigations (ESI-Fig. 8-10†) confirm that the counterion is located outside of II (Fig. 4a). In capsule I, however, the ion pair is encapsulated (ESI-Fig. 11-13†). The minute uptake of $\mathbf{6}^{+}$by neutral II is likely achieved by an energetically unfavorable charge separation in $\mathrm{CDCl}_{3}$. This could explain the low encapsulation ratio of $\mathbf{6}^{+}$by II. If so, the addition of the large base 7 (Table 1), which cannot be encapsulated due to its size, should increase the uptake of ammonium species: it would deprotonate the capsule and form an ion pair with the bromide outside the capsule, as depicted in Fig. 4b. Indeed, upon the addition of 7 , the encapsulation of ammonium species increases as anticipated (see also Table 1b). These findings solve the puzzling encapsulation behavior of capsule II and also explain the expulsion of encapsulated trihexylamine (5d) after HCl-addition $^{5 h}$ (Fig. 4c). After the addition of $\mathrm{HCl}$, the ion pair $\mathbf{5} \mathbf{d H}^{+} \mathrm{Cl}^{-}$is formed, which is rejected by capsule $\mathbf{I I}$.

The evidence presented clearly indicates that capsule II is able to stabilize cations inside its cavity due to cation- $\pi$ interactions. Therefore, its catalytic incompetence originates from a different source. After successful substrate uptake, protonation is required for substrate activation (Fig. 2). Although II is able to protonate amines (Table 1a), the acidity of the system may be too low for activation of the alcohol substrate. Therefore,

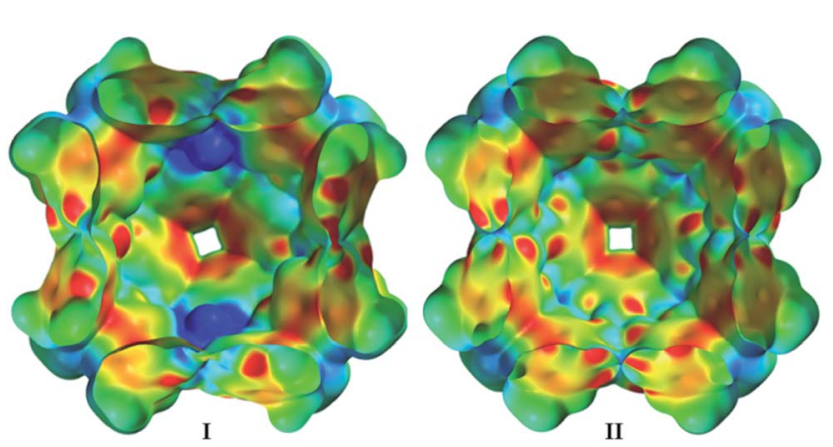

Fig. 3 Comparison of the inner electrostatic potential (ESP) surfaces of capsules I and II (for details see ESI Chapter $6 \dagger$ ). a)

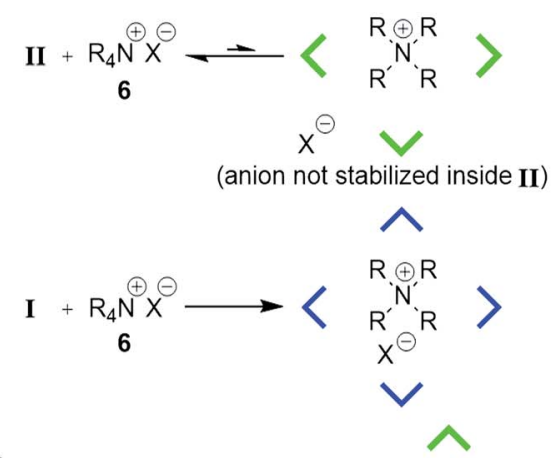

b)

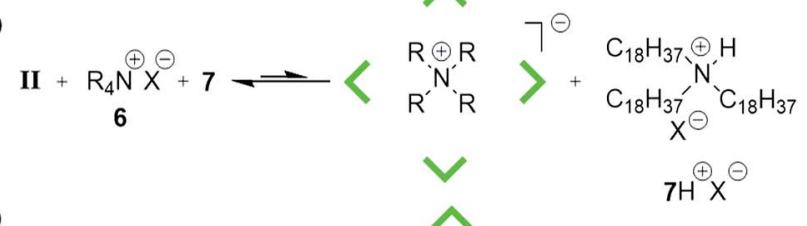

c)

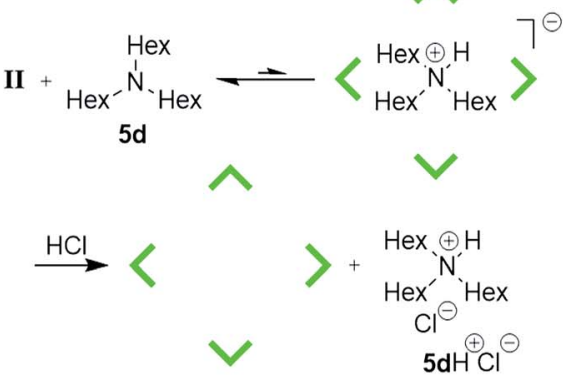

Fig. 4 Schematic representation of encapsulation experiments of alkylammonium salts and amines with capsule I and II. (a) In capsule II, anions are not encapsulated; while capsule I encapsulated the ion pair. (b) Addition of a large base increases the uptake of ammonium species. (c) Tertiary amines are encapsulated in protonated form inside II. After addition of a strong acid, an ion pair is formed which resists encapsulation.

the acidity of hexamer II was determined analogously to $\mathbf{I}^{2 a}$ by a series of protonation experiments with amines of varying basicity. The $\mathrm{p} K_{\mathrm{a}}$ value of capsule II is approx. 9.5-10 (see ESIFig. 15 and $16 ; \dagger c a$. four $\mathrm{p} K_{\mathrm{a}}$ units higher than resorcinarene capsule I). These results are in excellent agreement with our DFT calculations at the PBE-D3/def2-SVP $/ \varepsilon=4.81$ level of theory, suggesting that the proton affinity of $\mathbf{I}$ is $c a .5 \mathrm{kcal} \mathrm{mol}^{-1}$ lower than that of II (ESI-Fig. 18†). The surprisingly low acidity of II may be a result of mesomeric destabilization of the phenolate (ESI-Fig. 17 $\dagger$ ). Our DFT calculations further show that the anionic defect can delocalize across several hydrogen bonds in I, while we observe a more localized defect in II, leading to a lower relative $\mathrm{p} K_{\mathrm{a}}$ in capsule I (ESI-Fig. 19†). Therefore, the low acidity of II is the likely cause of its catalytic incompetence which prevents activation of the substrate by proton transfer (see also Fig. 2). We tried to overcome this limitation by the addition of stronger external acids (see ESI 4.3†), but could not observe a difference to the background reaction, caused by the acid added. This result, however, is not too surprising, since an external acid forms an ion pair with the substrate, which will resist encapsulation (see also Fig. 4c). 
The elucidation of the differences in these two systems allowed us to learn important lessons concerning catalytic activity in hydrogen-bond based molecular capsules. The identification of acidity as the crucial element of the catalytically active derivative $\mathbf{I}$ is essential for the design and construction of novel hydrogen bond-based supramolecular catalysts. These studies provided us with a first estimate on the required acidity for catalytic activity in such systems. Additionally, we demonstrated that externally added acid cannot function as a cocatalyst for capsule II since the substrate acid ion pairs formed are not encapsulated.

\section{Conclusions}

In conclusion, the differences between the closely related hexameric capsules I and II were elucidated for the first time. To the best of our knowledge this is the first study of two very closely related supramolecular host systems which completely differ in their catalytic activity. Evidence was presented showing that capsule II does not stabilize anions inside its cavity, as opposed to I. Therefore, alkyl ammonium salts are encapsulated only to a small extent with concomitant charge separation. Cations, nevertheless, are stabilized inside II even more strongly than inside I via cation $-\pi$ interactions. The much lower acidity of capsule II was determined to be the cause of its catalytic incompetence. These findings are of great significance for future developments in the field of enzyme-like catalysis and have a profound impact on the design of new hydrogen bondbased catalytically active host systems.

\section{Acknowledgements}

This project was supported by the Bayerischen Akademie der Wissenschaften (Junges Kolleg). V. R. I. K. is supported by grants from the Jane and Aatos Erkko Foundation and the German Research Foundation (DFG). We acknowledge the Leibniz Rechenzentrum (LRZ) and CSC - The IT Center for Science for computing time.

\section{Notes and references}

1 (a) D. M. Vriezema, M. Comellas Aragonès, J. A. A. W. Elemans, J. J. L. M. Cornelissen, A. E. Rowan and R. J. M. Nolte, Chem. Rev., 2005, 105, 1445-1490; (b) T. S. Koblenz, J. Wassenaar and J. N. H. Reek, Chem. Soc. Rev., 2008, 37, 247-262; (c) M. Yoshizawa, J. K. Klosterman and M. Fujita, Angew. Chem., Int. Ed., 2009, 48, 3418-3438; (d) J. Meeuwissen and J. N. H. Reek, Nat. Chem., 2010, 2, 615-621; (e) L. Marchetti and M. Levine, ACS Catal., 2011, 1, 1090-1118; $(f)$ M. J. Wiester, P. A. Ulmann and C. A. Mirkin, Angew. Chem., Int. Ed., 2011, 50, 114-137; $(g)$ M. Raynal, P. Ballester, A. Vidal-Ferran and P. W. N. M. van Leeuwen, Chem. Soc. Rev., 2014, 43, 17341787; (h) C. J. Brown, F. D. Toste, R. G. Bergman and K. N. Raymond, Chem. Rev., 2015, 115, 3012-3035; (i) S. H. A. M. Leenders, R. Gramage-Doria, B. de Bruin and J. N. H. Reek, Chem. Soc. Rev., 2015, 44, 433-448; (j)
S. Zarra, D. M. Wood, D. A. Roberts and J. R. Nitschke, Chem. Soc. Rev., 2015, 44, 419-432.

2 (a) Q. Zhang and K. Tiefenbacher, J. Am. Chem. Soc., 2013, 135, 16213-16219; (b) L. Catti and K. Tiefenbacher, Chem. Commun., 2015, 51, 892-894; (c) Q. Zhang and K. Tiefenbacher, Nat. Chem., 2015, 7, 197-202; (d) T. M. Bräuer, Q. Zhang and K. Tiefenbacher, Angew. Chem., Int. Ed., 2016, 55, 7698-7701; for reviews see $(e)$ L. Catti, Q. Zhang and K. Tiefenbacher, Synthesis, 2016, 48, 313-328; (f) L. Catti, Q. Zhang and K. Tiefenbacher, Chem.-Eur. J., 2016, 22, 9060-9066.

3 (a) G. Bianchini, G. L. Sorella, N. Canever, A. Scarso and G. Strukul, Chem. Commun., 2013, 49, 5322-5324; (b) G. Bianchini, G. La Sorella, N. Canever, A. Scarso and G. Strukul, Chem. Commun., 2013, 49, 5322-5324; (c) T. Caneva, L. Sperni, G. Strukul and A. Scarso, RSC Adv., 2016, 6, 83505-83509; (d) S. Giust, G. La Sorella, L. Sperni, F. Fabris, G. Strukul and A. Scarso, Asian J. Org. Chem., 2015, 4, 217-220; (e) G. La Sorella, L. Sperni, P. Ballester, G. Strukul and A. Scarso, Catal. Sci. Technol., 2016, 6, 60316036; (f) G. La Sorella, L. Sperni, G. Strukul and A. Scarso, ChemCatChem, 2015, 7, 291-296; (g) G. La Sorella, L. Sperni, G. Strukul and A. Scarso, Adv. Synth. Catal., 2016, 358, 3443-3449.

4 For pioneering work see (a) L. R. MacGillivray and J. L. Atwood, Nature, 1997, 389, 469-472; (b) L. Avram and Y. Cohen, Org. Lett., 2002, 4, 4365-4368; (c) L. Avram and Y. Cohen, J. Am. Chem. Soc., 2002, 124, 15148-15149; (d) A. Shivanyuk and J. Rebek, Proc. Natl. Acad. Sci. U. S. A., 2001, 98, 7662-7665; (e) A. Shivanyuk and J. J. Rebek, Chem. Commun., 2001, 2424-2425; $(f)$ A. Shivanyuk and J. Rebek, J. Am. Chem. Soc., 2003, 125, 3432-3433; for a review see $(g)$ L. Avram, Y. Cohen and J. Rebek Jr, Chem. Commun., 2011, 47, 5368-5375; for recent studies see $(h)$ S. Giust, G. La Sorella, L. Sperni, G. Strukul and A. Scarso, Chem. Commun., 2015, 51, 1658-1661; ( $i$ ) S. Giust, G. La Sorella, L. Sperni, F. Fabris, G. Strukul and A. Scarso, Asian J. Org. Chem., 2015, 4, 217-220; (j) G. La Sorella, L. Sperni, G. Strukul and A. Scarso, ChemCatChem, 2015, 7, 291-296.

5 For pioneering work see (a) T. Gerkensmeier, W. Iwanek, C. Agena, R. Frohlich, S. Kotila, C. Nather and J. Mattay, Eur. J. Org. Chem., 1999, 2257-2262; (b) J. L. Atwood, L. J. Barbour and A. Jerga, Chem. Commun., 2001, 23762377; (c) A. Shivanyuk and J. Rebek, Chem. Commun., 2001, 2374-2375, DOI: 10.1039/b106793c; (d) J. L. Atwood, L. J. Barbour and A. Jerga, Proc. Natl. Acad. Sci. U. S. A., 2002, 99, 4837-4841; (e) L. Avram and Y. Cohen, J. Am. Chem. Soc., 2003, 125, 16180-16181; (f) L. Avram and Y. Cohen, Org. Lett., 2003, 5, 3329-3332; $(g)$ A. Shivanyuk, J. C. Friese, S. Döring and J. Rebek, J. Org. Chem., 2003, 68, 6489-6496; (h) L. Avram and Y. Cohen, J. Am. Chem. Soc., 2004, 126, 11556-11563; for recent studies see $(i)$ V. Guralnik, L. Avram and Y. Cohen, Org. Lett., 2014, 16, 5592-5595; (j) L. Avram, A. Goldbourt and Y. Cohen, Angew. Chem., Int. Ed., 2016, 55, 904-907. 
6 (a) M. Yamanaka, A. Shivanyuk and J. Rebek, J. Am. Chem. Soc., 2004, 126, 2939-2943; (b) L. Avram and Y. Cohen, Org. Lett., 2003, 5, 1099-1102.

7 S. Yariv-Shoushan and Y. Cohen, Org. Lett., 2016, 18, 936-939.
8 (a) A. Ahman, M. Luostarinen, K. Rissanen and M. Nissinen, New J. Chem., 2007, 31, 169-177; (b) N. K. Beyeh and K. Rissanen, Isr. J. Chem., 2011, 51, 769-780.

9 S. Bartoli and S. Roelens, J. Am. Chem. Soc., 1999, 121, 1190811909. 